\title{
Pricing Scheme Choice: How Process Affects Outcome*
}

\author{
Natalia Shestakova ${ }^{\dagger}$
}

\author{
WP 411
}

\begin{abstract}
Standard price discrimination theories are based on the assumption that consumers use their future demand estimates to evaluate net utility of each pricing scheme and choose the scheme with the highest value. However, some evidence suggests that consumers might not always behave this way. The experiment presented in this paper shows that indeed a substantial proportion of subjects choose not to evaluate the net utility of the offered pricing schemes. Instead, they select from pricing schemes based on a comparison of the schemes' parameters. Interestingly, this selection approach leads to the correct pricing-scheme choice when subjects are not well aware of their demand, and to the incorrect choice when they are. The results call for alternative theories of price discrimination and corresponding policy implications.
\end{abstract}

\begin{abstract}
Abstrakt
Standardní teorie o cenové diskriminaci jsou založené na předpokladu, že spotřebitelé používají odhady své budoucí poptávky $\mathrm{k}$ vyhodnocení čistého užitku z každého oceňovacího schématu, a poté zvolí schéma s nejvyšší čistou hodnotou. Důkazy ale naznačují, že spotřebitelé se ne vždy chovají tímto způsobem. Experiment představený v tomto článku ukazuje, že podstatná část subjektů nevolí způsob, při kterém by vyhodnocovali čistý užitek z nabízených schémat. Místo toho vybírají oceňovací schémata na základě porovnání parametrů těchto schémat. Zajímavé na tomto je, že takovýto výběrový mechanismus vede ke správné volbě oceňovacího schématu $\mathrm{v}$ př́ípadech, kdy si subjekty nejsou vědomy své poptávky. Naopak, pokud znají svojí poptávku, pak toto vede k nesprávné volbě. Výsledky naznačují potřebu vytvoření alternativních teorií cenové diskriminace a jim odpovídajících regulačních pravidel.
\end{abstract}

Keywords: choice process, heuristics, price discrimination, experiment JEL classication: D42, D83

\footnotetext{
* I am grateful to Andreas Ortmann for supervising the project and to Katarína Kálovcová for her help with conducting the experiment. I also thank Peter Katuščák, Avner Shaked, Fabio Michelucci, Levent Celik, Libor Dušek and participants of the CERGE-EI experimental luncheon group for useful comments and conversations. This research was supported by GDN grant No. RRC IX-43. All opinions expressed are those of the author and have not been endorsed by the GDN.

$\uparrow$ Center for Economic Research and Graduate Education - Economic Institute, a joint workplace of Charles University in Prague and the Academy of Science of the Czech Republic.

Address: CERGE-EI, P.O. Box 882, Politickych veznu 7, Prague 1, 111 21, Czech Republic.

Email to Natalia.Shestakova@cerge-ei.cz.

This paper was supported by Center of Advanced Political Economy Research [Centrum pro pokročilá politicko-ekonomická studia], No. LC542, (2005-2009)
} 


\section{Introduction}

Consider an environment in which a consumer has to select a pricing scheme prior to consumption of a homogeneous good. This appears to be a complicated task and there seems to be no consensus on how consumers undertake it. The standard price discrimination literature implicitly assumes that consumers search for the most valuable pricing scheme by evaluating all alternatives one after another. Experimental evidence on the choice of [artificial] gambles suggests that, instead, consumers tend to follow heuristics, especially when the choice problem is complicated (see e.g., Brandstatter et al. 2006 and Rubinstein et al. 2010).

The experiment presented in this paper makes it possible to identify whether consumers carefully evaluate all available pricing schemes or whether they use simpler decision rules also in riskless choice. In the experiment, subjects first work through a consumption task to learn their demand and then select from two three-part pricing schemes to define the cost of the subsequent consumption. The two selection approaches compared in this paper predict different distributions of incorrect pricing scheme choices across five experimental treatments. The analysis of choices made by subjects suggests that they are more likely to use simple, and sometimes misleading, decision rules than to evaluate all pricing schemes carefully one after another.

The experiment is computer-based and makes use of a mouse tracking tool, Mouselab, to collect process data on the pricing-scheme choice. The data facilitates subject grouping, depending on how subjects process the choice relevant information. It appears that comparison of the schemes' parameters, rather than evaluation of each scheme separately, helps in finding the most appropriate pricing scheme when subjects are not well aware of their demands. When they are aware of their demands, that strategy works not as well. These conclusions would not be possible with field data.

Knowing how consumers choose pricing schemes is important in at least two domains. First, this knowledge is used to model consumer behavior in Industrial Organi- 
zation. For instance, in theories of price discrimination via non-linear pricing, ${ }^{1}$ when demand is the private knowledge of consumers, a seller faces a set of incentive feasibility constraints $^{2}$ on the menu of pricing schemes offered. This implicitly assumes that each consumer evaluates each pricing scheme and then chooses the one with the highest level of net utility. Once it can be assumed that consumers choose not to evaluate each pricing scheme, or have predictable biases in evaluating them, then the set of constraints that the seller has to satisfy changes substantially. So does the profit-maximizing set of pricing schemes. ${ }^{3}$

Knowing how consumers choose pricing schemes is also of interest to regulatory authorities focused on consumer protection. The European Commission's proposal to review the telecom regulatory framework is one example. As part of the proposed reform, providers of telecom services should be "obliged to publish information on prices so that consumers can more easily compare the different offers on the market." 4 However, the Commission does not specify what it means for different offers to be more easily comparable.

The main contribution of this paper is to shed light on selection approaches in pricing-scheme choice and their effects on the resulting choice. The considered choice problem and the predictions of two alternative selection approaches are formally presented in Section 3. The experimental design and specific features of the data collected in controlled sessions are discussed in Section 4. Section 5 contains data analysis and main results. Concluding remarks are summarized in Section 6.

\footnotetext{
${ }^{1}$ Seminal papers are Mussa \& Rosen 1978 and Maskin \& Riley 1984. More recent examples can be found in, e.g., Armstrong 1996 and Hamilton \& Slutsky 2004. A good textbook reference is Laffont \& Martimort 2002.

${ }^{2}$ This set includes participation and incentive compatibility constraints for each consumer type.

${ }^{3}$ For the case when consumers have predictable biases in evaluating future utility due to timeinconsistent behavior, see Della Vigna \& Malmendier 2004, Eliaz \& Spiegler 2006, and Esteban et al. 2007. The case of consumers' incomplete evaluation of net utilities from all available options has not yet been considered in the price discrimination literature (see Ellison 2006 for a review).

${ }^{4}$ http://ec.europa.eu/information_society/policy/ecomm/tomorrow/reform/index_en.htm
} 


\section{Related Literature}

Two approaches to pricing-scheme selection are compared in this paper. The standard one assumes that a consumer would carry out the following three steps to choose a pricing scheme. First, she would get information on all available pricing schemes. Second, she would evaluate her optimal consumption level under each pricing scheme. Most importantly, she would compute her expected net utility from each pricing scheme given the optimal consumption decision, and select the one with the highest expected net utility. An alternative approach is based on developments in economics and psychology to be discussed below. This approach deviates from the standard one in that a consumer is assumed to use simpler decision rules. In this way she responds to the presence of various constraints.

First attempts to describe consumer behavior in the presence of search costs were undertaken within optimization-under-constraints models (Stigler 1961 being a seminal paper). Applied to pricing-scheme choice, where only cognitive constraints are present, optimization under constraints suggests that the consumer would evaluate one pricing scheme and then the costs and benefits from evaluating another pricing scheme. If the costs are lower than the benefits, she will evaluate the second scheme and will choose the scheme with the highest value. Otherwise, she will choose the first scheme.

The major critique to the optimization-under-constraints models is that it is cognitively more demanding to evaluate the costs and benefits of evaluating the next option than to evaluate the option itself (see e.g., Gigerenzer et al. 1999). In this regard, the satisficing concept introduced by Herbert A. Simon (see e.g., Simon 1955) is more appealing. It postulates that the evaluation process would continue as long as an a priori set adjustable aspiration level is achieved. That is, if the consumer can achieve a certain utility level with the evaluated pricing scheme, she will not consider other schemes at all.

In both cases, the optimization-under-constraints and the satisficing models, noth- 
ing is said about the choice of the first option to be evaluated. ${ }^{5}$ In particular, based on their experimental evidence, they suggest that a decision-maker first observes the parameters of the alternatives in her choice set, then eliminates some of the alternatives based on easy-to-implement criteria, and only then evaluates the remaining ones (Tversky 1972). More generally, they propose that instead of evaluating each alternative, the decision-maker is likely to use various heuristics when choosing among them (Tversky \& Kahneman 1974). To the best of my knowledge, these ideas have never been applied to the choice of pricing schemes.

The experimental evidence gave rise to a number of alternative theories of decision making. With a few exceptions (see Hey et al. 2008), these theories are generalizations of the expected utility theory. Namely, they explain certain deviations from supposedly optimal behavior by modifying the decision makers' objective function. ${ }^{6}$ The major objection to extending expected utility theory (see e.g., Gigerenzer et al. 1999) is that adding more parameters into the model improves its fitting ability (so that the collected data will be explained) but not its predictive power (so that it is not guaranteed that new data will be predicted correctly), while economists are more interested in the latter.

As an alternative approach to understanding decision-making processes, the ABC research group has developed the idea of simple heuristics (Gigerenzer et al. 1999). They claim that, when dealing with choice problems, rather than maximizing any objective function, people use simple comparison rules. For example, Brandstatter et al. 2006 introduce the priority heuristic that allows making risky choices without trade-offs. This heuristic is capable of predicting the majority of biases observed in the experiments where subjects had to choose between lotteries. However, it is impossible to distinguish whether subjects use heuristics or maximize some odd objective functions when only information on their actual choices is available.

The last issue has been addressed in Johnson et al. 2008. The authors propose that

\footnotetext{
${ }^{5}$ In addition, within the satisficing concept, it is not clear how the aspiration level is set.

${ }^{6}$ For a comprehensive summary of emergent theories and an investigation of their potential superiority over the expected utility theory, see Hey \& Orme 1994. The authors show that such superiority is, in fact, questionable.
} 
process models should be tested using process data that can be collected with a tool like Mouselab, which is used in the present study. Previously, this tool was adopted in Johnson et al. 2002 to demonstrate that subjects deviate from backward induction in sequential bargaining games, and in Gabaix et al. 2006 to show that the directed cognition model predicts the sequence of steps in the information acquisition process better than the fully rational model. Also, an alternative process tracking tool, iView, that records eye movements, has been used in Rubinstein et al. 2010 to conclude that decision-makers are more likely to compare prizes and their probabilities separately when choosing between lotteries.

\section{Consumer Choice Problem}

\subsection{Problem Setup}

In this paper, the consumer choice problem is substantially simplified: her choice set consists of two three-part pricing schemes. ${ }^{7}$ The three parts are a fixed fee, $F_{i}$, to be paid at the beginning of a consumption period, a bundle of inclusive units, $I_{i}$, which are provided without any additional charge after the fixed fee is paid, and an extra unit price, $p_{i}$, to be paid for units consumed in addition to the inclusive units, where $i=\{1,2\}$ refers to a pricing scheme. ${ }^{8}$ The pricing-scheme choice is preceded by a consumption period, during which the consumer is charged a flat per-unit price, $p_{0}$, and has a chance to learn her demand. She knows that in the second consumption period, where she will pay according to the chosen pricing scheme, the demand will be exactly the same as in the first period. Thus, there is no demand uncertainty in the consumer problem. ${ }^{9}$ However, as consumers have to learn their demands in the first

\footnotetext{
${ }^{7}$ On the assumption that preferences over pricing schemes are complete, a consumer should define whether, for any pair of pricing schemes, $X$ and $Y$, she prefers $X$ to $Y$, or $Y$ to $X$, or is indifferent, no matter how many pricing schemes she is offered.

${ }^{8}$ Plans are numbered such that $F_{2}>F_{1}$. This paper focuses on the case when this also implies that $I_{2}>I_{1}$ and $p_{2}<p_{1}$ as is common for mobile phone plans.

${ }^{9}$ Elimination of demand uncertainty is done for the same reason as restriction of the number of pricing schemes to two. This allows me to concentrate on the process of defining preferences in a
} 
consumption period, some of them might end up not being fully aware of their demand.

Regarding the demand, I assume that consumers evaluate consumption units categorically, and that there are only two categories. That is, consumers assign a high value, $v_{A}$, to one group of consumption units, and a low value, $v_{B}$, to another group. ${ }^{10}$ Then the demand is characterized by the number of high-valued units, $\bar{A}_{j}$, and the number of low-valued units, $\bar{B}_{j}$, where $j$ refers to consumer type. I introduce two demand types: high-demand type $\left(\bar{A}_{H}, \bar{B}_{H}\right)$ and low-demand type $\left(\bar{A}_{L}, \bar{B}_{L}\right)$ with $\bar{A}_{H}>\bar{A}_{L}$ and $\bar{B}_{H}>\bar{B}_{L} \cdot{ }^{11}$

Under this demand specification, the consumer problem is the following. She knows her high and low consumption values, $v_{A}$ and $v_{B}$, before consumption starts. In the first consumption period, high-valued and low-valued consumption units arrive in a random order and she has to decide which of them to accept. I consider the case when $v_{A}>p_{0}>v_{B}$, which means it is utility maximizing for the consumer to accept all highvalued units and to reject all low-valued units. One possibility to learn the associated number of high-valued units, $\bar{A}_{j}$, is to count them during the first consumption period. The availability of the second possibility depends on the consumption decisions. If they are reasonable, that is, all high-valued and no low-valued units are taken, then a simple arithmetic operation, division of the generated consumption value ${ }^{12}$ by the net value of a high-valued unit, $v_{A}-p_{0}$, gives the total number of high-valued units.

simple choice problem. The intuition suggests that if consumers choose not to evaluate each alternative separately when there are just two of them and there is no uncertainty, then they will be even more inclined not to do so in more complicated situations.

${ }^{10}$ Despite all the insights into categorical reasoning that we have (see e.g., Laurence \& Margolis 1999, Murphy 2002 for overviews, and Mohlin 2009 for an attempt to model categorical reasoning), consumers are generally not allowed to categorize consumption units when it comes to defining demand function. This prevents the demand function from being discontinuous. In the experiment, there is no need to maintain the continuity assumption. Therefore, I intentionally impose categorization of consumption units.

${ }^{11}$ As an example, consider the following. A PhD student uses internet connection at home to maintain email communication with his professor (a high-valued consumption of megabites) and check updates on Facebook (a low-valued consumption of megabites given that the student is not an addict). The professor uses internet connection for the same purposes and assigns the same values to the two categories. However, the professor spends less time at home (and communicates with the student mainly from the office). As a result, the number of megabites to be potentially spent from home on both emails and Facebook is higher for the student than for the professor.

${ }^{12} \mathrm{I}$ stick to the term "consumption value of pricing scheme $\mathrm{X}$ " meaning "net utility of consumption given that pricing scheme $\mathrm{X}$ is chosen". 
Incorrect consumption decisions make it more difficult to learn the associated number of high-valued units, $\bar{A}_{j}$.

After the first consumption period is over, the consumer has to choose a pricing scheme, $\left(F_{1}, I_{1}, p_{1}\right)$ or $\left(F_{2}, I_{2}, p_{2}\right)$, knowing that in the second consumption period she will face the same sequence of high-valued and low-valued units as in the first period. The pricing schemes are designed such that, in addition to information that is explicitly given, only the knowledge of $\bar{A}_{j}$ is important for the correct choice as it is straightforward to realize that consumption of $B$-units is not optimal, no matter how many of them the consumer has (see Fig.5). ${ }^{13}$ After the scheme is chosen, the second consumption period starts. In that period, the sequence of consumption units is indeed the same as in the first period but the cost of consumption is determined by the chosen pricing scheme.

\subsection{Pricing-Scheme Choice}

All existing models of price discrimination implicitly assume that consumers compare the net consumption values of each pricing scheme to decide which one to choose. This is true for classical models with perfectly rational consumers (Armstrong 2006, Stole 2007 provide a broad overview of this literature), as well as for alternative models (Eliaz \& Spiegler 2008, Uthemann 2005, Grubb 2009) where consumers are subject to various biases in estimating their future utility but they still go through the evaluation of each pricing scheme.

What might be called the evaluative approach to pricing scheme selection assumes that the following questions are answered with respect to each pricing scheme: (1) how many high-valued and low-valued units is it optimal to consume, (2) what is the total value and the total cost of this consumption, (3) what is the net consumption value. After the net consumption values associated with each scheme are computed, their comparison determines the most favorable scheme. Under this approach, no direct

\footnotetext{
${ }^{13}$ All figures can be found in Appendix C.
} 
comparison of schemes' parameters (fixed fees, inclusive units, or extra unit prices) is needed.

The evaluative approach to pricing scheme selection does not necessarily lead to the correct pricing-scheme choice. In the just described setup, an incorrect choice may occur if the consumer did not succeed in learning the number of high-valued units assigned to her, or made a computational mistake. In the first case, when the consumer is not sure about $\bar{A}_{j}$, she still needs to hold some belief about $\bar{A}_{j}$ to proceed with the evaluative approach. Then the probability of an error in the pricing scheme choice depends on the range of beliefs about $\bar{A}_{j}$ where the ex-post optimal pricing scheme dominates its alternative. The probability of error is lower when this range is higher.

In contrast to the evaluative approach, the comparative approach to pricing-scheme selection does not require computation of net consumption values. Instead, it allows for "rules of thumb", intuitive judgments, educated guesses, and common sense, and the comparison of the offered pricing schemes' parameters.

Generally, it might be not possible to distinguish the comparative approach from the evaluative one using data on pricing scheme choices only. The reason is the big variety of decision rules within the comparative approach ${ }^{14}$ and overlapping of their predictions for pricing scheme choices with each other and with those of the evaluative approach.

The following decision rule is particularly interesting since it can be distinguished from the evaluative approach using data on the chosen pricing schemes (see Section 4.3). It includes the following steps: (1) compute the difference in the fixed fees of the two pricing schemes offered, (2) compute the difference in the corresponding included units, (3) compute the cost of an additional unit received as part of the second scheme's inclusive bundle, (4) take the second scheme if the cost of the additional unit received as part of its bundle is "sufficiently low". With this decision rule, the probability of error in the pricing scheme choice does not depend on the range of beliefs about $\bar{A}_{j}$

\footnotetext{
${ }^{14}$ Several decision rules are described in Appendix A.
} 
where the ex-post optimal pricing scheme dominates its alternative, as opposed to the evaluative approach.

This paper contains two types of data analysis: the analysis of choice outcomes and the analysis of choice processes. In the first type of analysis, the described decision rule is used for generating predictions of the comparative approach. There are two reasons for this. First, it was the approach used by participants of pilot sessions who were later asked to describe their decision rules. Second, this decision rule yields predictions substantially different from those of the evaluative approach, which is not always the case with other decision rules. In the second type of data analysis, there is no need to specify the decision rule within the comparative approach (see Section 4.3).

\section{Experiment}

\subsection{Design}

To implement the problem of pricing scheme selection introduced in the previous section, three tasks are given to subjects. The first task replicates the first consumption period. The values of demand parameters are shown in Table $1 .{ }^{15}$ Assignment of demand types (low or high) to the subjects is done randomly.

Before the task starts, the values of $\mathrm{A}$ - and B-units and the unit price appear on subjects' screens. During the task, a sequence of A- and B-units appears shown in Fig.1. ${ }^{16}$ Every subject is charged a unit price of 6 Experimental Currency Units $(E C U)$ for each unit accepted in the first task. The subjects have to decide whether to accept or reject an offered unit depending on its category. To ensure that the duration of the consumption task is the same for all subjects, a subject has 4 seconds for each decision if she is of the high-demand type and 6 seconds for each decision if she is of the low-demand type. Thus, the total duration of the consumption task is 3 minutes.

\footnotetext{
${ }^{15}$ All tables can be found in Appendix B.

${ }^{16}$ All figures can be found in Appendix C.
} 
From the first task, a subject can earn $120 E C U$ if she is of the high-demand type and $80 E C U$ if she is of the low-demand type. ${ }^{17}$ The cost of not accepting an A-unit is $4 E C U$, while the cost of accepting a B-unit is $3 E C U$ for both types. After the task is completed, the earned wealth is displayed to the subject (see Fig.2).

With the second experimental task, the main question of the paper is addressed: How do consumers approach the pricing-scheme choice? Two pricing schemes are offered to the subjects (see Fig.3). The parameters of the two schemes vary across five treatments as shown in Table 2. To incentivize the subjects financially, they are told that one scheme allows them to achieve higher earnings than another in the subsequent consumption task. In addition, a bonus of $20 E C U$ is paid to them for choosing the payoff maximizing scheme. The subjects are also told that answering a set of questions listed below the table with the pricing schemes' parameters can help in finding the best scheme (see Fig.4). ${ }^{18}$ The variations in pricing schemes across treatments allow identification of the selection approach using choice data, while the set of optional questions is helpful in identifying the selection approach using process data (see Section 4.3 for more details). The second task has a time limit of 15 minutes.

After the scheme is chosen, the third experimental task starts. In that task, the same sequence of units as in the first task is offered to the subjects. Upon the correct pricing scheme choice, a subject can earn at most $100 E C U$ if she is of the high-demand type and $80 E C U$ if she is of the low-demand type regardless of the treatment. In this case, also the $20 E C U$ bonus is also added after the task is completed. With a suboptimal pricing scheme, the maximum possible earnings vary between $80 E C U$ and $90 E C U$ for the high-demand type and between $30 E C U$ and $35 E C U$ for the low-demand type depending on the treatment.

\footnotetext{
${ }^{17}$ Different transfer rates are used for the high- and the low-demand types (see Section 4.2 ), such that the potential earnings from the experiment are the same for the two types.

${ }^{18} \mathrm{~A}$ set of guiding questions is provided in order to induce subjects to evaluate each pricing scheme and to observe what mouse movements are associated with this process.
} 


\subsection{Implementation}

Data from the web-based experiment were collected in six sessions for which undergraduate students of Charles University in Prague were invited to the CERGE-EI computer lab with 20 machines on which the experimental web-page was pre-loaded. Sessions were conducted between April - June 2009. A total of 96 participants showed up.

General information about the experiment was read aloud. Subjects were assured that everyone could earn the same amount ${ }^{19}$ and that their earnings would depend on their own performance but not on the performance of others. Afterwards, they proceeded at their individual pace. ${ }^{20}$ Before detailed instructions for the experimental tasks were given to the subjects, they were asked to complete a personality quiz. After a subject read the detailed instructions, she was asked to fill in missing values in two practice examples. To make sure that the instructions were understood correctly, it was not possible to proceed until correct answers were submitted. ${ }^{21}$

After the experiment was over, each subject was asked to fill in a final questionnaire, and was paid afterwards. The experiment, including reading the instructions and filling in the questionnaires, took, on average, about one hour. From the experimental tasks, subjects could earn up to $240 E C U$ (the high-demand type) or up to $180 E C U$ (the lowdemand type). To equalize the real payoffs for the two types, I used different transfer rates for different types. This was $2 C Z K$ to $1 E C U$ for the low-demand type and 1.5 CZK to $1 E C U$ for the high-demand type in Sessions $1-4$ and $3.2 C Z K$ to $1 E C U$ for the low-demand type and 2.4 CZK to $1 E C U$ for the high-demand type in Sessions $5-6$. Thus, the maximum possible payoff from the experimental tasks was $360 C Z K$ in Sessions $1-4$ and $580 C Z K$ in Sessions $5-6$. The maximum possible overall payoff was $610 C Z K$ in Sessions $1-2,460 C Z K$ in Sessions $3-4$, and $680 C Z K$ in Sessions

\footnotetext{
${ }^{19}$ This amount varied across sessions as I expected that the value of time was higher in the later sessions that were conducted during the exam period.

${ }^{20}$ The version without the personality quiz and with shortened consumption tasks for a low-type consumer in treatment 1 is located at http://home.cerge-ei.cz/shestakova/Experiment/enter.html. Use the password "flower" to enter the experiment. The experiment works properly only with the Mozilla Firefox browser.

${ }^{21}$ Contact the author for the complete set of instructions and practice examples.
} 
$5-6 .^{22}$

\subsection{Data and Identification of Selection Approach}

The imposed variations in the parameters of the pricing schemes (Table 2) affect the pricing scheme choice in different directions depending on whether the evaluative or the comparative approach is used (see Sections 3.2 for details). This makes it possible to identify the most commonly used selection approach by analyzing the distribution of incorrect choices across five experimental treatments.

In all five treatments, it is optimal for the low-demand type $\left(\bar{A}_{L}=20\right)$ to choose Plan 1 and for the high-demand type $\left(\bar{A}_{H}=30\right)$ to choose Plan 2 . When subjects follow the evaluative approach, the difficulty is that for making the correct choice they need to learn $\bar{A}_{j}$ from the preceding consumption task. If this is not done and the incorrect belief regarding $\bar{A}_{j}$ is taken, then the evaluative approach leads to more errors in those treatments where the incorrect scheme dominates the correct scheme for a wider range of beliefs regarding $\bar{A}_{j}$. The domination areas are shown in Table 3 and depicted graphically in Fig.5. The numbers in Table 3 represent the net consumption values of the two pricing schemes in different treatments assuming different beliefs regarding $\bar{A}_{j}$. The resulting predictions of the evaluative approach presented in Table 5 also reflect the variation in the cost of an error across treatments.

Under the comparative approach, the alternative decision rule introduced in Section 3.2 requires computation of the cost of an additional unit received as part of the inclusive bundle with Plan 2. Higher cost makes Plan 1 more attractive, and subjects are more likely to choose Plan 1 in the corresponding treatments (see Table 4). Given that Plan 1 is the correct choice for the low-demand type and the incorrect choice for the high-demand type, higher cost is associated with a lower predicted share of incorrect

\footnotetext{
${ }^{22}$ In addition to the performance-based payoff, the subjects recieved $50 C Z K$ for completing a personality quiz prior to the experiment. Also, they recieved $50 C Z K$ for answering a set of questions at the end of the experiment in Sessions 3-6, and up to $200 C Z K$ for participating in an additional experiment that took about 30 min in Sessions 1-2.
} 
choices for the low-demand type and a higher share for the high-demand type (Table 5). The evaluative approach and the considered decision rule under the comparative approach give different predictions regarding the proportions of incorrect choices in different treatments. This offers one possibility to identify the selection approach. ${ }^{23}$

As Johnson et al. 2008 propose, a better understanding of the selection process can be achieved by using data on the selection process itself rather than data on the outcome. The Mouselab tool allows me to detect the order of information processing during pricing scheme selection. This is achieved by covering the parameters of the pricing schemes with their labels and making it possible to observe only one parameter a time. To open the value of a parameter of interest, a subject has to point at the corresponding label with her mouse. ${ }^{24}$ The Mouselab tool records all mouse transitions between parameters in real time.

To use the sequence of information acquisition for making judgements about the selection process requires a belief that judgements can inferred from mouse movements. Such a belief is supported by other economists using the Mouselab tool. ${ }^{25}$ However, a so-called reading effect (see e.g., Brandstatter et al. 2008) should be controlled for. The essence of the reading effect is that subjects tend to move the mouse from left to right and from up to down without any evaluation of the information that they obtain when they open the values of the parameters.

Typically, the reading effect is minimized by randomizing the order in which pieces of information are presented to the subject. I chose not to randomize because the way pricing schemes are offered to consumers in practice does not impose such random-

\footnotetext{
${ }^{23}$ It was also possible to consider other decision rules. However, other decision rules would yield predictions that would substantially overlap either with those of the evaluative approach or those of the already considered decision rule. The outcome data would not be sufficient for identifying which approach is more precise.

${ }^{24} \mathrm{An}$ illustration of how Mouselab WEB works can be found at its webpage: http://www.mouselabweb.org

${ }^{25}$ Previously, the Mouselab was used in Costa-Gomes et al. 2001, Costa-Gomes \& Crawford 2006, Gabaix et al. 2006, Johnson et al. 2002, Johnson et al. 2008. Costa-Gomes et al. 2001 and CostaGomes \& Crawford 2006 illustrate that the distortions in choices caused by the Mouselab environment, and in particular, the fact that to acquire information a subject needs to move his mouse, are minimal. Gabaix et al. 2006 note "upper-down" and "left-to-right" search biases.
} 
ization. Alternatively, Klayman 1983 and Johnson et al. 2008 separate reading and choice phases of the decision making process at the data analysis stage. They do so by casting away all the transitions made before all important pieces of information have been examined at least once. In my case, this solution would leave too few observations for the analysis.

My solution assumes that if a subject has a tendency to open the information in a certain order, this has a permanent effect on the sequence of mouse transitions over the whole selection process. The idea is to induce the subjects to follow the evaluative approach over one part of the selection process and to let them acquire the information in the way they would do it naturally over the rest of the selection process. Then, the differences in mouse transitions at the "evaluative" and the "natural" stages would suggest which selection approach the subjects use while controlling for possible reading effects by differencing them out.

To induce the subjects to follow the evaluative approach, the description of pricing schemes is followed by a questionnaire that suggests the steps needed to compute the net consumption value of each pricing scheme (Fig.4). ${ }^{26}$ To see the questionnaire, the subjects need to scroll down the page from the table with the parameters of the pricing schemes. This setup allows me to assume that they see the questionnaire after they decide which scheme to choose. I, therefore, take the moment when the questionnaire is addressed for the first time (captured by the Mouselab tool) as separating the natural stage from the evaluative stage of the selection process.

\footnotetext{
${ }^{26}$ Answering the posed questions is voluntary. However, subjects are told that this might help them choose the correct plan. 54 subjects answered all questions, 14 others answered a large enough share to claim that they used the questionnaire as guidance. Notably, the proportions of incorrect choices of pricing schemes are nearly the same among those who used the questionnaire (34\%) and those who did not $(32 \%)$.
} 


\section{Results}

Of the 96 subjects that participated in the experiment, 32 made an incorrect pricingscheme choice. The distribution of incorrect choices across demand types and treatments is shown in Table 6. This distribution suggests that the low-demand subjects were likely to use the specified decision rule and not the evaluative approach. However, the same cannot be said of the high-demand subjects. The result is based on the four Fisher's exact tests shown in Table 7. In each test, the null hypothesis is that there is no variation in the distribution of incorrect pricing scheme choices across treatments. This is tested against a one-sided alternative, that this distribution can be predicted by the corresponding selection approach for the corresponding demand type.

Result 1. The distribution of incorrect pricing-scheme choices across treatments for the low-demand type can be predicted by the comparative approach to pricing scheme selection but not by the evaluative one. Neither of the approaches predicts the distribution of incorrect choices for the high-demand type.

However, for the high-demand type, the comparative approach predicts the sign of the differences across treatments, though they are not statistically significant. The evaluative approach fails in predicting the sign.

More importantly, the analysis of the choice data can only suggest which approach is used by the majority of subjects, not by an individual subject. Identification of an individual selection approach is possible, however, with process data. The main idea behind the identification strategy, as it follows from the discussion in Section 4.3, is to compare mouse movements at the natural and evaluative stages of the selection process. A higher proportion of horizontal movements at the natural stage would suggest that the comparative approach is used more intensively. ${ }^{27}$

To reduce the noise caused by random movements, only returned mouse movements,

\footnotetext{
${ }^{27}$ Note that it is also possible for the horizontal movements to be prevalent within the evaluative approach. Then the selection process with a dominating share of horizontal movements should be classified as "evaluating pricing schemes through comparison of their parameters". The difference in labeling does not affect the main results that follow, namely, those presented in Tables 13 and 14 .
} 
that is, movements from element $x$ to element $y$ and back to element $x$, are considered in the analysis. ${ }^{28}$ To control for the fact that some subjects might generally move the mouse more intensively than others, the shares of horizontal returned movements in the overall number of returned movements rather than their absolute numbers are compared between the two stages (Fig.6).

Result 2. The paired t-test for the differences in the shares of horizontal returned movements in all such movements between the natural (on average 44\%) and the evaluative (on average 28\%) stages of the selection process (Table 8) suggests that most subjects were using the comparative approach to pricing scheme selection more intensively than the evaluative one.

With the process data, it is possible to characterize each subject's selection approach by the difference in the share of the horizontal returned mouse movements between the natural and the evaluative stages of the selection process. A higher share indicates more intensive usage of the comparative approach in the natural stage. The effect of the selection approach on the probability of error in the pricing scheme choice can then be estimated.

Both variables, the probability of error and the selection approach indicator, are likely to depend on subjects' awareness of their demand. I assume that awareness is determined by the performance in the preceding consumption task. The justification is that when all high-valued units are accepted and all low-valued units are rejected, the only important demand characteristic, $\bar{A}_{j}$, can be computed directly from the realized earnings. ${ }^{29}$ A subject is identified as being aware of her demand if the total proportion of rejected high-valued units and accepted low-valued units is below $5 \%$. This criterion identifies 52 subjects as being aware of their demand. In addition, 3 subjects who

\footnotetext{
${ }^{28}$ There are, correspondingly, 15 and 9 subjects with no returned movements at the natural and the evaluative stages. These subjects are assigned zero shares of returned horizontal movements and dummy variables are created to distinguish them.

${ }^{29} \mathrm{In}$ fact, $30 \%$ of subjects out of those $30 \%$ who answered the question confirmed that they used this method for learning their demand characterstics when they were asked "Were you counting how many units A you had in Task 1" in the final questionnaire.
} 
revealed their awareness otherwise are moved to this group. ${ }^{30}$

Another factor that is likely to affect both the probability of error and the selection approach is a subject's general understanding of the experimental tasks. To control for this factor, the number of attempts to answer the practice questions in the instructions is used. A subject is identified as confused in the experimental tasks if she used more than one extra attempt to answer these practice questions. This strategy identified 49 confused subjects. ${ }^{31}$

The effect of the selection approach on the probability of error in the pricing scheme choice is estimated with a probit model (Table 9a). Confusion with the experimental tasks, demand awareness, demand type, and the absence of returned movements at each stage are used as controls.

Result 3. Overall, the approach to pricing-scheme selection seems to have no effect on the probability of incorrect pricing-scheme choice.

At the same time, there is a strong effect of demand awareness on the probability of incorrect pricing scheme choice $(38.5 \%)$, which indicates that the choice problem was more complicated for those subjects who were not aware of their demands. Previous research (see e.g., Rubinstein et al. 2010) suggests that the selection approach might be determined by the difficulty level of the problem. Moving one step further, I expect that also the effect of the selection approach on the probability of incorrect choice depends on the difficulty level, that is, on the demand awareness. To test for this, the joint effect of the demand awareness and the selection approach is allowed in the model estimated in Table $9 \mathrm{~b}$.

Result 4. Using the comparative approach more intensively, that is, increasing the difference in the share of horizontal returned movements between the two stages by 0.1, when being not aware of the demand, reduces the probability of error in pricing

\footnotetext{
${ }^{30}$ These subjects used the correct number of high-valued units when they were computing net consumption values of the pricing schemes.

${ }^{31}$ The number is high because the identification criterion allows only for one extra attempt and thus captures even slight confusion. Once three extra attempts are allowed, there are only 24 confused subjects.
} 
scheme choice by $6 \%$, whereas doing so when being aware of the demand, increases the probability of error by $3.9 \% .{ }^{32}$

As can be seen from Table 9c, these effects do not change when the treatment effects are controlled for. The treatment effects themselves are not significant. Also, note that in all three specifications of the model, confusion in the experimental tasks does not directly affect the probability of choosing the incorrect pricing scheme, nor does the demand type. However, the absence of returned movements at the natural stage is associated with a lower probability of choosing the incorrect scheme.

\section{Conclusion}

The analysis presented in this paper demonstrates that the comparative approach predicts the distribution of incorrect pricing sheme choices and the sequence in which the schemes' parameters are observed better than the evaluative approach does. When subjects are not well aware of their demand, the comparative approach helps them find the most appropriate pricing scheme. In contrast, when they are aware of their demand, use of the comparative selection approach increases the probability of choosing the incorrect pricing scheme.

The primary implication of these results concerns potential constraints on pricing schemes imposed by regulatory authorities. The design of pricing schemes should not be exploitative. If the comparison of pricing schemes' parameters indicates that a particular pricing scheme is the best choice for consumers with certain demand levels, then this scheme should indeed be associated with the highest net consumption values for these consumers.

\footnotetext{
${ }^{32}$ When subjects are not aware of their demand (dummy=1), the effect of the selection approach on the probability of error is equal to the sum of the coefficients on the selection approach measure $(0.39)$ and the interaction of this measure with the awareness dummy $(-0.99)$. When subjects are aware of their demand, the effect is represented by the first coefficient only. The difference in the share of returned horizontal movements between the natural and the evaluative stages of the selection approach is used as its measure. The change in this difference by 0.1 leads to the effects stated in Result 4.
} 
One example where this rule was violated comes from the Czech mobile market in the spring of 2008. Mobile tariffs were offered that provided certain number of inclusive minutes, but they were not the best choice for consumers whose optimal consumption was in the range of this number. Although impossible to check empirically, we could suspect that many those consumers chose such exploitative mobile tariffs.

The results presented in this paper call for alternative theories of price discrimination. Such theories should consider the possibility that there exists a match function between consumers' demand characteristics and the parameters of pricing schemes, which is maximized by consumers when they choose a pricing scheme. This match function would be generally different from the expected utility function. However, the latter could be treated as a special case. 


\section{References}

Armstrong, M. (1996, January). Multiproduct nonlinear pricing. Econometrica $64(1), 51-75$.

Armstrong, M. (2006, October). Recent Developments in the Economics of Price Discrimination, Chapter 4, pp. 97-141. Advances in Economics and Econometrics: Theory and Applications, Ninth World Congress. New York, NY: Cambridge University Press.

Brandstatter, E., G. Gigerenzer, and R. Hertwig (2006, April). The priority heuristic: Making choices without trade-offs. Psychological Review 113(2), 409-432.

Costa-Gomes, M. A. and V. P. Crawford (2006, December). Cognition and behavior in two-person guessing games: An experimental study. American Economic Review 96(5), 1737-1768.

Costa-Gomes, M. A., V. P. Crawford, and B. Broseta (2001, September). Cognition and behavior in normal-form games: An experimental study. Econometrica 69(5), $1193-1235$.

Della Vigna, S. and U. Malmendier (2004, May). Contract design and self-control: Theory and evidence. The Quarterly Journal of Economics 119(2), 353-402.

Eliaz, K. and R. Spiegler (2006, July). Contracting with diversely naive agents. Review of Economic Studies 73(3), 689-714.

Eliaz, K. and R. Spiegler (2008, December). Consumer optimism and price discrimination. Theoretical Economics 3(4), 459-497.

Ellison, G. (2006, October). Bounded Rationality in Industrial Organization, Chapter 5, pp. 142-184. Advances in Economics and Econometrics: Theory and Applications, Ninth World Congress. New York, NY: Cambridge University Press.

Esteban, S., E. Miyagawa, and M. Shum (2007, July). Nonlinear pricing with selfcontrol preferences. Journal of Economic Theory 135(1), 306-338.

Gabaix, X., D. Laibson, G. Moloche, and S. Weinberg (2006, September). Costly information acquisition: Experimental analysis of a boundedly rational model. American Economic Review 96(4), 1043-1068.

Gigerenzer, G., P. M. Todd, and the ABC Research Group (1999). Simple Heuristics That Make Us Smart. Oxford University Press.

Grubb, M. D. (2009, December). Selling to overconfident consumers. American Economic Review 99(5), 1770-1807.

Hamilton, J. and S. Slutsky (2004, June). Nonlinear price discrimination with a finite number of consumers and constrained recontracting. International Journal of Industrial Organization 22(6), 737-757.

Hey, J. D., G. Lotito, and A. Maffioletti (2008, April). The descriptive and predictive adequacy of theories of decision making under uncertainty/ambiguity. Discussion Papers 08/04, Department of Economics, University of York. 
Hey, J. D. and C. Orme (1994, November). Investigating generalizations of expected utility theory using experimental data. Econometrica 62(6), 1291-1326.

Johnson, E. J., C. Camerer, S. Sen, and T. Rymon (2002, May). Detecting failures of backward induction: Monitoring information search in sequential bargaining. Journal of Economic Theory 104(1), 16-47.

Johnson, E. J., M. Schulte-Mecklenbeck, and M. C. Willemsen (2008, January). Process models deserve process data: Comment on Brandstatter, Gigerenzer, and Hertwig (2006). Psychological Review 115(1), 263-272.

Klayman, J. (1983). Analysis of predecisional information search patterns, pp. 401414. Analysing and Aiding Decision Processes. Budapest.

Laffont, J.-J. and D. Martimort (2001). The Theory of Incentives: The PrincipalAgent Model. Princeton University Press.

Laurence, S. and E. Margolis (1999). Concepts and Cognitive Science, pp. 3-81. Concepts: Core Readings. MIT Press.

Maskin, E. and J. Riley (1984). Monopoly with incomplete information. RAND Journal of Economics 15(2), 171-196.

Mohlin, E. (2009, May). Optimal categorization. Working Paper Series in Economics and Finance 721, Stockholm School of Economics.

Murphy, G. (2004). The Big Book of Concepts. MIT Press.

Mussa, M. and S. Rosen (1978, August). Monopoly and product quality. Journal of Economic Theory 18(2), 301-317.

Rubinstein, A., A. Arieli, and Y. Ben-Ami (2010). Tracking decision makers under uncertainty. manuscript, School of Economics, Tel Aviv University.

Simon, H. A. (1955, February). A behavioral model of rational choice. The Quarterly Journal of Economics 69, 99-118.

Stigler, G. J. (1961). The economics of information. Journal of Political Economy 69, 213.

Stole, L. A. (2007, June). Price Discrimination and Competition, Volume 3 of Handbook of Industrial Organization, Chapter 34, pp. 2221-2299. Elsevier.

Tversky, A. (1972, July). Elimination by aspects: A theory of choice. Psychological Review 79(4), 281-299.

Tversky, A. and D. Kahneman (1974). Judgement under uncertainty: Heuristics and biases. Science 185(4157), 1124-1131.

Uthemann, A. (2005). Competitive screening of customers with non-common priors. manuscript, Department of Economics, University College London. 


\section{Appendix A: Decision Rules under the Compara- tive Approach}

The first decision rule to consider is very simple as it does not require any computations. However, it relies on a good knowledge of demand characteristics. Rule\#1 is the following:

- evaluate the maximum possible number of high-valued units, $\bar{A}_{j}$.

- compare this number with the number of inclusive units within each pricing scheme, $\dot{I}_{1}$ and $I_{2}$.

- select the scheme with the number of inclusive units which is closest to $\bar{A}_{j}$.

The next three decision rules ignore demand characteristics completely. The first two are extremely naive and very likely to lead to incorrect choices of pricing schemes. Rule\#2 is to choose "the cheapest" scheme, that is, the one with the lowest fixed fee. Rule\#3 is to choose "the most flexible" pricing scheme, that is, the one with the highest inclusive bundle. Another decision rule from this group is more advanced as it involves some computations. Rule\#4 is the following:

- inquire the highest number of inclusive units, $I_{2}$.

- compute how much has to be paid for this consumption within the scheme with the lowest number of inclusive units. ${ }^{33}$

- select the scheme with the lowest cost of consuming $I_{2}$.

Those consumers who use rules\#1-4 can be easily cheated by firms. However, if firms do not design pricing schemes in an exploitative way, these consumers will do well with little cognitive effort.

There also exists a decision rule that minimizes the number of computations but still leads a consumer to the same decision as the evaluative approach. Same as rule\#1, rule\#5 is conditional on a good knowledge of demand characteristics. In fact, it requires a "partial" evaluation of pricing schemes. To understand how it works, consider the following example:

- after the maximum possible number of high-valued units, $\bar{A}_{j}$, was evaluated, the parameters of both pricing schemes, $\left(F_{1}, I_{1}, p_{1}\right)$ and $\left(F_{2}, I_{2}, p_{2}\right)$, were inquired and extra unit prices were compared with high- and low- values, $v_{A}$ and $v_{B}$, the following result was obtained: $\bar{A}_{j}=I_{2}>I_{1}, v_{A}>p_{1}>p_{2}>v_{B}$

- then only $F_{1}+p_{1}\left(\bar{A}_{j}-I_{1}\right)$ has to be computed and compared with $F_{2}$.

Of course, with a different result obtained from the comparison of demand characteristics with pricing schemes' parameters, different computations have to be performed. The point here is that some computations required by the evaluative approach will be eliminated through careful comparison of parameters.

\footnotetext{
${ }^{33}$ It is equal to the fixed fee of this scheme plus the extra unit price multiplied by the difference in the number of inclusive units of the two schemes, $F_{1}+p_{1}\left(I_{2}-I_{1}\right)$.
} 


\section{Appendix B: Tables}

Table 1: Parameters of demand profiles

\begin{tabular}{ccc}
\hline \hline Parameter & Low-demand type & High-demand type \\
\hline Value of A (high) & $10 \mathrm{ECU}$ & $10 \mathrm{ECU}$ \\
Value of B (low) & $3 \mathrm{ECU}$ & $3 \mathrm{ECU}$ \\
Number of As & 20 units & 30 units \\
Number of Bs & 10 units & 15 units \\
\hline
\end{tabular}

Table 2: Parameters of pricing schemes

\begin{tabular}{|c|c|c|c|c|}
\hline Parameter & $\begin{array}{l}\text { Plan } 1 \\
\end{array}$ & $\overline{\text { Plan } 2}$ & $\begin{array}{l}\text { Plan } 1 \\
\end{array}$ & $\overline{\text { Plan } 2}$ \\
\hline & \multicolumn{2}{|c|}{ Treatment 1} & \multicolumn{2}{|c|}{ Treatment 3} \\
\hline Fixed Fee & $120 \mathrm{ECU}$ & $200 \mathrm{ECU}$ & $120 \mathrm{ECU}$ & $180 \mathrm{ECU}$ \\
\hline Included Units & 20 units & 30 units & 20 units & 25 units \\
\hline Extra Unit Price & $11 \mathrm{ECU}$ & 5 ECU & $11 \mathrm{ECU}$ & 4 ECU \\
\hline & \multicolumn{2}{|c|}{ Treatment 2} & \multicolumn{2}{|c|}{ Treatment 4} \\
\hline Fixed Fee & $120 \mathrm{ECU}$ & $200 \mathrm{ECU}$ & $120 \mathrm{ECU}$ & $180 \mathrm{ECU}$ \\
\hline Included Units & 20 units & 30 units & 20 units & 25 units \\
\hline Extra Unit Price & $9 \mathrm{ECU}$ & $5 \mathrm{ECU}$ & $9 \mathrm{ECU}$ & $4 \mathrm{ECU}$ \\
\hline \multicolumn{5}{|c|}{ Treatment 5} \\
\hline Fixed Fee & $75 \mathrm{ECU}$ & $200 \mathrm{ECU}$ & & \\
\hline Included Units & 15 units & 30 units & & \\
\hline Extra Unit Price & $9 \mathrm{ECU}$ & $5 \mathrm{ECU}$ & & \\
\hline
\end{tabular}


Table 3: Dominance areas of Plan 1 over Plan 2 across treatments. In bold are the areas where Plan 1 is more valuable than Plan 2. Within the evaluative approach, the low-demand type should make the correct choice when she holds a belief corresponding to the area in bold, and the incorrect choice when she holds a different belief. The opposite is true for the high-demand type.

\begin{tabular}{cccccc}
\hline \hline Belief for $\bar{A}_{j}$ & Treat 1 & Treat $2 \& 5$ & Treat 3 & Treat 4 \\
\hline $\bar{A}_{j}=20$ & $\mathbf{8 0}$ vs. $\mathbf{3 0}$ & $\mathbf{8 0}$ vs. $\mathbf{3 0}$ & $\mathbf{8 0}$ vs. $\mathbf{3 5}$ & $\mathbf{8 0}$ vs. $\mathbf{3 5}$ \\
$\bar{A}_{j}=25$ & $\mathbf{8 0}$ vs. $\mathbf{6 5}$ & $\mathbf{8 5}$ vs. $\mathbf{6 5}$ & $\mathbf{8 0}$ vs. $\mathbf{7 0}$ & $\mathbf{8 5}$ vs. $\mathbf{7 0}$ \\
$\bar{A}_{j}=26$ & $\mathbf{8 0}$ vs. $\mathbf{7 2}$ & $\mathbf{8 6}$ vs. $\mathbf{7 2}$ & $\mathbf{8 0}$ vs. $\mathbf{7 6}$ & $\mathbf{8 6}$ vs. $\mathbf{7 6}$ \\
$\bar{A}_{j}=27$ & $\mathbf{8 0}$ vs. $\mathbf{7 9}$ & $\mathbf{8 7}$ vs. $\mathbf{7 9}$ & 80 vs. 82 & $\mathbf{8 7}$ vs. $\mathbf{8 2}$ \\
$\bar{A}_{j}=28$ & 80 vs. 86 & $\mathbf{8 8}$ vs. $\mathbf{8 6}$ & 80 vs. 88 & $\mathbf{8 8}$ vs. $\mathbf{8 8}$ \\
$\bar{A}_{j}=29$ & 80 vs. 93 & 89 vs. 93 & 80 vs. 94 & 89 vs. 94 \\
$\bar{A}_{j}=30$ & 80 vs. 100 & 90 vs. 100 & 80 vs. 100 & 90 vs. 100 \\
\hline \multicolumn{5}{c}{ Ranking by attractiveness of Plan 1} \\
Rank:
\end{tabular}

Table 4: Cost of an additional unit recieved as part of an inclusive bundle with Plan 2 across treatments. The higher this cost, the more attractive is Plan 1 in comparison with Plan 2. Under the comparative approach, the low-demand type is more likely to make the correct choice in the treatments with stronger attractiveness of Plan 1 . The opposite holds for the high-demand type.

\begin{tabular}{ccc}
\hline \hline Treat $1 \& 2$ & Treat $3 \& 4$ & Treat 5 \\
\hline 8 ECU & 12 ECU & 8.3 ECU \\
\hline Ranking by & attractiveness of Plan 1 \\
IV, V & I, II & III \\
\hline
\end{tabular}

Table 5: Predictions of the two selection approaches for the distribution of incorrect pricing scheme choices across treatments.

\begin{tabular}{ccccc}
\hline \hline & \multicolumn{2}{c}{ Evaluative approach } & \multicolumn{2}{c}{ Comparative approach } \\
\hline & High share of & Low share of & High share of & Low share of \\
& incorrect choices & incorrect choices & incorrect choices & incorrect choices \\
\hline Low-demand type & T1, T3 & T2, T4, T5 & T1, T2, T5 & T3, T4 \\
High-demand type & T2, T4, T5 & T1, T3 & T3, T4 & T1, T2, T5 \\
\hline
\end{tabular}


Table 6: Distribution of incorrect choices across demand types and treatments

\begin{tabular}{ccccccccccccc}
\hline \hline & \multicolumn{2}{c}{ T1 } & \multicolumn{2}{c}{ T2 } & \multicolumn{2}{c}{ T3 } & \multicolumn{2}{c}{ T4 } & \multicolumn{2}{c}{ T5 } & \multicolumn{2}{c}{ Total } \\
& low & high & low & high & low & high & low & high & low & high & low & high \\
\hline $\begin{array}{c}\text { \#incorrect } \\
\text { choices }\end{array}$ & 4 & 3 & 7 & 3 & 1 & 4 & 1 & 1 & 5 & 2 & 18 & 13 \\
\hline \# obs & 11 & 9 & & & & & & & & & & \\
& Total: & 20 & Total: & $\mathbf{3 1}$ & Total: $\mathbf{2 0}$ & Total: $\mathbf{9}$ & Total: $\mathbf{1 6}$ & Total: $\mathbf{9 6}$ \\
\hline
\end{tabular}

Table 7: Identifying selection approach using outcome data (Fisher's exact tests). For each segment, the null hypothesis is that there is no difference in the distribution of incorrect choices across treatments. P-value listed first is the probability that the null is true when compared to the alternative that the distribution is as predicted by the corresponding selection approach. P-value listed in brackets is the probability that the null is true when compared to the alternative that the distribution is opposite to the one predicted by the corresponding selection approach.

\begin{tabular}{|c|c|c|c|c|}
\hline & \multicolumn{2}{|c|}{ Evaluative approach } & \multicolumn{2}{|c|}{ Comparative approach } \\
\hline & treatments & treatments & treatments & treatments \\
\hline & w/ predicted & $\mathrm{w} /$ predicted & $\mathrm{w} /$ predicted & $\mathrm{w} /$ predicted \\
\hline & high share of & low share of & high share of & low share of \\
\hline & incorect choices & incorrect choices & inncorrect choices & incorect choices \\
\hline & \multicolumn{4}{|c|}{ Low-demand type (49 obs) } \\
\hline Incorrect choice & 5 & 13 & 16 & 2 \\
\hline Correct choice & 16 & 15 & 19 & 12 \\
\hline 1-tail p-values & \multicolumn{2}{|c|}{$.97(.09)$} & \multicolumn{2}{|c|}{$.04(.99)$} \\
\hline & \multicolumn{4}{|c|}{ High-demand type (47 obs) } \\
\hline Incorrect choice & 6 & 7 & 5 & 8 \\
\hline Correct choice & 22 & 12 & 10 & 24 \\
\hline 1-tail p-values & \multicolumn{2}{|c|}{$.93(.2)$} & \multicolumn{2}{|c|}{$.4(.83)$} \\
\hline
\end{tabular}

Table 8: Identifying selection approach using process data: between-stage differences in shares of returned horizontal transitions for each individual (paired T-test).

\begin{tabular}{|c|c|c|}
\hline \multicolumn{3}{|c|}{ Share of horizontal movements } \\
\hline & $\begin{array}{l}\text { Natural } \\
\text { stage }\end{array}$ & $\begin{array}{c}\text { Evaluative } \\
\text { stage }\end{array}$ \\
\hline mean & .44 & .28 \\
\hline stand.dev. & $(.33)$ & $(.27)$ \\
\hline \# observ. & \multirow{2}{*}{\multicolumn{2}{|c|}{$\begin{array}{c}96 \\
3.91^{* * *}\end{array}$}} \\
\hline t-stat. & & \\
\hline
\end{tabular}


Table 9: Probit of incorrect pricing scheme choice

\begin{tabular}{|c|c|c|c|}
\hline \multirow[t]{2}{*}{ Dependent variable } & \multicolumn{3}{|c|}{ Incorrect pricing scheme choice } \\
\hline & (a) & (b) & (c) \\
\hline Selection approach measure & $\begin{array}{l}-.0629 \\
(.1532)\end{array}$ & $\begin{array}{l}.3881^{*} \\
(.2045)\end{array}$ & $\begin{array}{l}.3846^{*} \\
(.2057)\end{array}$ \\
\hline Dummy for not being aware of demand & $\begin{array}{l}.3847^{* * *} \\
(.0972)\end{array}$ & $\begin{array}{l}.5814^{* * *} \\
(.1067)\end{array}$ & $\begin{array}{l}.583^{* * *} \\
(.1076)\end{array}$ \\
\hline $\begin{array}{l}\text { Dummy for being confused } \\
\text { with experiment }\end{array}$ & $\begin{array}{l}-.0079 \\
(.1047)\end{array}$ & $\begin{array}{l}.046 \\
(.1028)\end{array}$ & $\begin{array}{l}.0187 \\
(.0187)\end{array}$ \\
\hline High-demand type & $\begin{array}{l}-.085 \\
(.1028)\end{array}$ & $\begin{array}{l}-.098 \\
(.1016)\end{array}$ & $\begin{array}{l}-.1083 \\
(.1012)\end{array}$ \\
\hline $\begin{array}{c}\text { Dummy for no returned movements at } \\
\text { natural stage }\end{array}$ & $\begin{array}{l}-.2694^{*} \\
(.103)\end{array}$ & $\begin{array}{l}-.2923^{* *} \\
(.0826)\end{array}$ & $\begin{array}{l}-.314^{* *} \\
(.0757)\end{array}$ \\
\hline $\begin{array}{c}\text { Dummy for no returned movements at } \\
\text { evaluative stage }\end{array}$ & $\begin{array}{l}-.0958 \\
(.1685)\end{array}$ & $\begin{array}{l}-.0357 \\
(.1653)\end{array}$ & $\begin{array}{l}-.05 \\
(.1626)\end{array}$ \\
\hline Selection approach measure* & & $-.989^{* * *}$ & $-.9887^{* * *}$ \\
\hline * Dummy for not being aware of demand & & $(.3102)$ & $(.313)$ \\
\hline Treatment 2 & & & $\begin{array}{l}.0816 \\
(.157)\end{array}$ \\
\hline Treatment 3 & & & $\begin{array}{l}-.0494 \\
(.15)\end{array}$ \\
\hline Treatment 4 & & & $\begin{array}{l}-.0903 \\
(.16)\end{array}$ \\
\hline Treatment 5 & & & $\begin{array}{l}.0238 \\
(.1713)\end{array}$ \\
\hline \multirow[t]{2}{*}{ \# observations } & 96 & 96 & 96 \\
\hline & $\begin{array}{l}*-10 \% \mathrm{~s} \\
\text { * }^{* *}-5 \% \mathrm{~s} \\
\text { *** }^{*}-1 \%\end{array}$ & $\begin{array}{l}\text { gnificance } \\
\text { gnificance } \\
\text { ignificance }\end{array}$ & $\begin{array}{l}\text { level } \\
\text { level } \\
\text { level }\end{array}$ \\
\hline
\end{tabular}

Note: Entries in the table represent the marginal coefficients of the probit in response to an infinitesimal change in the continuous variables, and a discrete change for the dummy variables.

Standard errors in parentheses. 


\section{Appendix C: Figures}

\section{Task 1: Consumption}

Here you can always check the price, your benefits from both actions and your current wealth.

To check the content of a cell, point out the mouse at it:

\begin{tabular}{|l|l|l|l|l|}
\hline \hline Flat Price & Benefit from action A & Benefit from action B & Wealth \\
\hline
\end{tabular}

\section{Do you want to buy action $\mathbf{A}$ ?}

$$
\circ \text { YES } \odot \text { NO }
$$

You have 3 sec

Fig.1: Screen-shot of consumption task.

\section{Task 1: Consumption}

Congratulations!

You successfully completed Task 1: Consumption. Your current wealth is 16 ECU. Click on "Go to Task 2" button to continue.

Go to Task 2

Fig. 2: Screen-shot of consumption task. Displayed wealth. 


\section{Task 2: Plan Choice}

You have 15 minutes for completing this task

This timer shows how much time has passed $1 \mathrm{~min}: 3 \mathrm{sec}$

After the time expires, all cells will become inactive. Then choose one of the two plans to continue the experiment. You may also choose a plan and move to Task 3: Consumption Again before the time expires.

Two plans of the same three-part structure are offered to you. You may learn the parameters of these plans from the table below.

\begin{tabular}{|c|c|c|}
\hline Plan 1 & Plan 2 & Benefit from Action $A$ \\
\hline Fixed Fee 1 & Fixed Fee 2 & Benefit from Action B \\
\hline Inclusive Actions 1 & Inclusive Actions 2 & Bonus \\
\hline Unit Price 1 & Unit Price 2 & Your Wealth \\
\hline
\end{tabular}

The parameters of the plans have the following meaning:

- A Fixed Fee is similar to the monthly fee in mobile phone plans:

- Fixed Fee 1 specifies how much you have to pay for getting Inclusive Actions in Task 3: Consumption Again if you choose Plan 1. - Fixed Fee 2 specifies how much you have to pay for getting Inclusive Actions in Task 3: Consumption Again if you choose Plan 2

- Inclusive Actions are similar to the inclusive minutes in mobile phone plans:

- Inclusive Actions 1 specify how many actions in Task 3: Consumption Again you will get "for free", that is, without paying a Unit Price

- In them, if you choose Plan 1.
. for them, if you choose Plan 2.

- A Unit Price is similar to the unit price in mobile phone plans:

- Unit Price 1 specifies how much you have to pay for every action that you decide to buy in Task 3: Consumption Again after the

- Unit Price 2 specifies how much you have to pay to

for every action that you decide to buy in Task 3: Consumption Again after the Inclusive Actions are over if you choose Plan 2 .

Also, you may check Benefits from actions A and B specified by your demand profile and your current Wealth in the table.

Of the two plans offered to you, one is more suitable for your demand profile than the other. If you make a correct choice, you will be paid a Bonus after you complete the subsequent Task 3.

Fig. 3: Screen shot of pricing scheme selection task. Natural stage

Answering the following questions may help you to choose the right plan. Specify your answers in the empty fields (optionally):

First, answer these questions assuming that you will choose Plan 1:

What will be you consumption strategy in Task 3 if you choose Plan 1 :

How many actions A will you buy in Task 3 if you choose Plan 1:

How many actions B will you buy in Task 3 if you choose Plan 1:

What will be your total benefit from this consumption in Task 3 if you choose Plan 1 :

What will be your total expenditure on this consumption in Task 3 if you choose Plan 1 .

What will be your payoff (net benefit) in Task 3 if you choose Plan 1 .

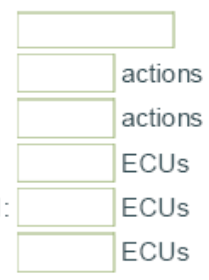

Now, answer the same questions assuming that you will choose Plan 2:

What will be you consumption strategy in Task 3 if you choose Plan 2 :

How many actions A will you buy in Task 3 if you choose Plan 2:

How many actions B will you buy in Task 3 if you choose Plan 2:

What will be your total benefit from this consumption in Task 3 if you choose Plan 2:

What will be your total expenditure on this consumption in Task 3 if you choose Plan 2

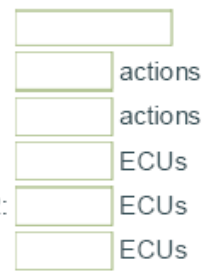

What will be your payoff (net benefit) in Task 3 if you choose Plan 2:

Fig. 4: Screen-shot of pricing scheme selection task. Imposed evaluative stage. 


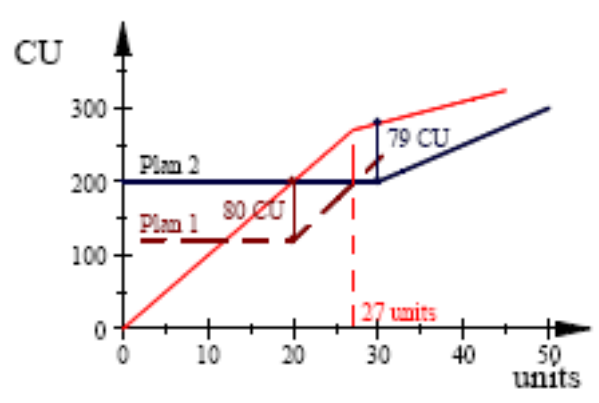

T1: Plan 1 is dominant for $\bar{A}_{j} \leq 27$

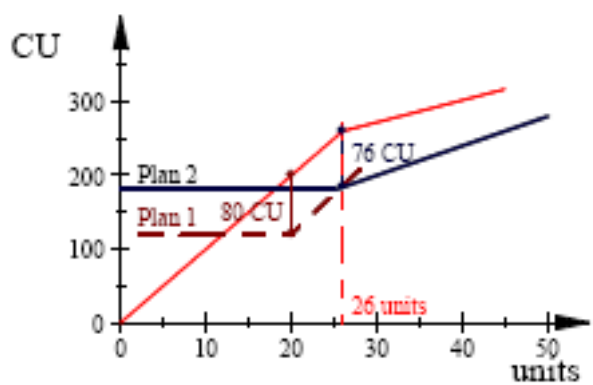

T3: Plan 1 is dominant for $\bar{A}_{j} \leq 26$

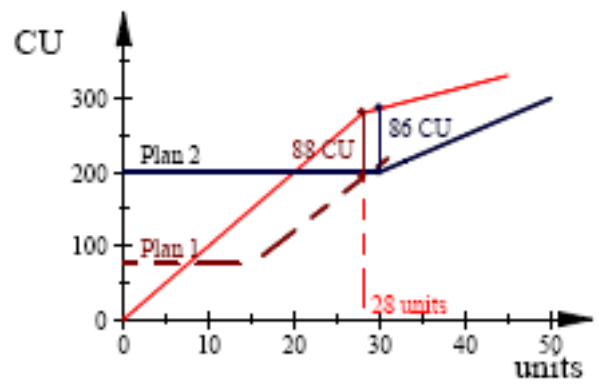

T5: Plan 1 is dominant for $\bar{A}_{j} \leq 28$

Fig. 5: Marginal beliefs regarding $\bar{A}_{j}$ in the experimental treatments. Under the evaluative approach, a weaker belief (the kink of the dashed red line is closer to the origin) leads to the choice of Plan 1, and a stronger belief (the kink of the dashed red line is further from the origin) leads to the choice of Plan 2. 


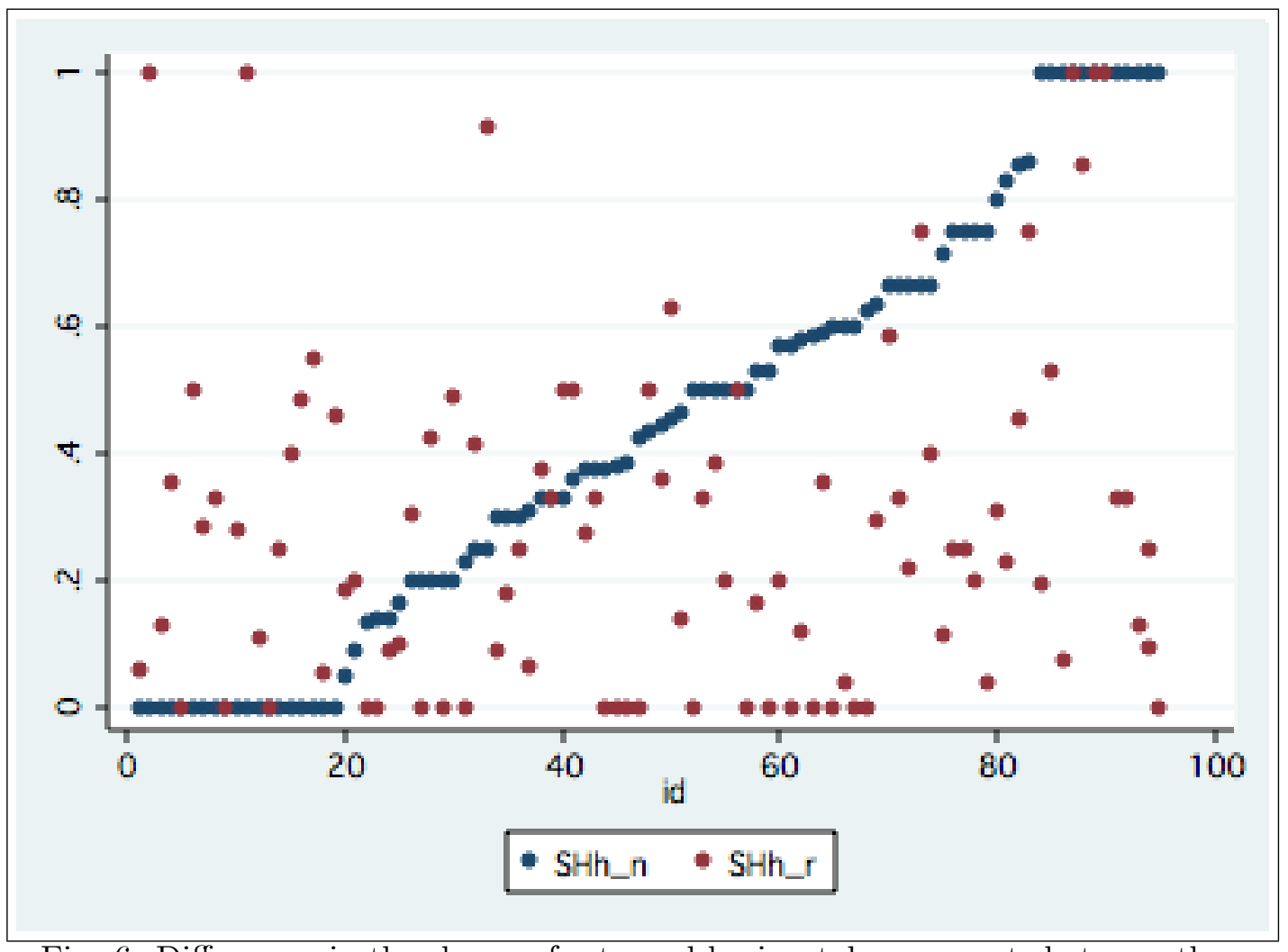

Fig. 6: Differences in the shares of returned horizontal movements between the natural (SHh_n) and the evaluative (SHh_r) stages of the selection process.

Overall, these shares were identical for 8 subjects, were higher at the natural stage for 59 subjects, and were lower at the natural stage for 29 subjects. 